\title{
Effect of creatine ethyl ester supplementation and resistance training on hormonal changes, body composition and muscle strength in underweight non-athlete men
}

\author{
Hamid Arazi ${ }^{1}$, Ehsan Eghbali ${ }^{1}$, Mahmood Karimifard ${ }^{2}$ \\ ${ }^{1}$ Department of Exercise Physiology, Faculty of Sport Sciences, University of Guilan, Rasht, Iran; ${ }^{2}$ Department of Exercise \\ Physiology, University Campus, University of Guilan, Rasht, Iran
}

\section{Summary}

Study aim: The aim of this study to determine whether creatine ethyl ester (CEE) supplementation combined with resistance training (RT) is effective for improving hormonal changes, body composition and muscle strength in underweight non-athlete men.

Materials and methods: Sixteen underweight non-athlete men participated in this double-blind study and were randomly assigned to one of two groups: RT with placebo (RT + PL, $n=8)$ and RT with CEE supplementation $(\mathrm{RT}+\mathrm{CEE}, \mathrm{n}=8)$. The participants performed 6 weeks of RT (60-80\% 1RM) combined with CEE or PL. 48 hours before and after the training period, muscle strength (1RM for leg press and bench press), body composition (percentage of body fat, circumference measurements of the arm and thigh), serum levels of testosterone, cortisol, and growth hormone (GH) of the participant were measurements. Results: Significant increases were observed for weight, muscle strength and muscle mass, serum levels of testosterone and $\mathrm{GH}$ between pre and post-test in the RT + CEE group $(\mathrm{p}<0.05)$. In addition, cortisol level was significantly decreased in the post-test in the RT + CEE group. The decrease in fat percent was greater in the RT + PL group than in the RT + CEE group (\%change $=-6.78$ vs. -0.76 , respectively). Weight and leg strength changes in the RT + CEE group were significant compared to the RT + PL group ( $<<0.001, p=0.05, p=0.001$; respectively). However, in other variables, despite the increase of GH and testosterone levels and lower levels of cortisol in the RT + CEE group, no significant differences were observed between the two groups $(\mathrm{p}<0.05)$.

Conclusion: It seems that the consumption of CEE combined with RT can have significant effects on body weight and leg strength in underweight non-athlete men. This supplement may provide a potential nutritional intervention to promote body weight in underweight men.

\section{Keywords: Skinny - Muscle strength - Resistance training - Growth hormone - Creatine ethyl ester}

\section{Introduction}

Resistance training (RT) is known as a factor enhancing functional abilities and health status; primary adaptation is due to RT of skeletal muscle hypertrophy. RT improves body composition through an increase in fat free mass, which mainly consists of increased muscle mass and reduced fat mass [40]. RT is a powerful stimulus for changing hormonal secretions (various anabolic and catabolic hormones, especially testosterone and cortisol) [24]. Acute RT, given the intensity and volume of exercise and the amount of rest, can produce a hormone response. Muscle activity causes a series of mechanical and chemical changes in the muscle through hormone signaling and regulation of the activity of enzymes [8]. The anabolic environment of the body increases by stimulating exercise with the availability of food, supplements and hormones. It seems that use of protein supplements affects the hormonal responses involved in muscle metabolism such as insulin, testosterone, GH, cortisol, estrogen, and insulin-like hormones, and thus affects the muscle protein and energy balance of the body [8].

Suitable diets and adequate calorie intake, hydration and timing of food intake are factors that are important 
for athletic performance and recovery. However, there are some dietary supplements which can enhance individual performance in addition to the effects of exercise, including creatine [8]. Sufficient and balanced diet is important to increase muscle strength and size in RT. Proper food consumption during RT is needed to maximize protein synthesis and minimize protein breakdown, restore muscle fuel storage and euhydration [8].

The supplement creatine has been widely studied since the 1990s, and numerous studies have examined its effects on maximum strength and body mass increase [36]. With creatine supplementation, free creatine and phosphate-creatine stored in muscle can be increased, which improves energy production by an anaerobic system at the beginning of physical activity. Also, this increase in phosphocreatine can help increase protein synthesis and prevent proteolysis in muscle tissue [36]. Creatine is found in small amounts in the brain, liver, kidney, and testicles, while approximately $95 \%$ of the stored creatine is present in skeletal muscle. Creatine is supplied by external sources such as fish and red meat, and is synthesized from the amino acids arginine, glycine and methionine [3, 23, 38]. Body energy is provided by the hydrolysis of ATP to ADP and P. The phosphagen system provides ATP reintroduction to ADP using phosphocreatine (PCr) through the reversible creatine kinase reaction. $95 \%$ of the creatine stored in skeletal muscle; of this, approximately $40 \%$ is free creatine and $60 \%$ is $\mathrm{PCr}[3,38]$. It has been shown that creatine compounds have an effect on hormonal control, especially in the context of changes in endogenous testosterone, while physical activity together with use of this category of supplements also alters the metabolic responses of the body more. This is reflected by an increase in serum levels of certain hormones in the blood such as $\mathrm{GH}$, testosterone and cortisol, and simultaneously causes changes in skeletal muscle (increased volume, tension, and strength) [37].

Creatine is a popular energy supplement in sports nutrition. However, creatine supplementation sometimes causes side effects such as gastrointestinal complications, muscular cramps and weight gain. Most studies have been done on creatine monohydrate [1]. Creatine supplementation increases the amount of muscle creatine (20 to $40 \%$ ) in individuals with low muscle creatine levels [10]. By taking 20 grams of creatine per day for 5 days (divided into four daily doses) in a loading phase, the amount of muscle creatine can be increased. Afterwards, increasing creatine stores in the muscles can be maintained by the daily intake of 2 to 5 grams of creatine supplementation (maintenance phase). However, the variability of the increase in muscle creatine in people is very variable and can range from 0 to $40 \%$ [27]. Creatine has several forms and one of its types is creatine ethyl ester (CEE). CEE is an ethanol esterified with creatine and may improve bioavailability [1]. CEE seems to be a new substrate for creatine kinase, and the production forms phosphocreatine ethyl ester, which may be a source of energy in the muscles and brain [1].

The FDA has introduced CEE as a novel food based on manufacturers' requests. A daily dose of 0.5 to 5 grams is recommended at a maximum dose of 30 grams. No adverse effects were reported on body weight, liver, kidney, or histopathological analyses of some organs, including the liver and kidneys, in mice receiving an equivalent of 30 grams per person of $70 \mathrm{~kg}$ for 7 days [1]. The role of CEE is not well defined; studies have shown that CEE is converted to creatine in the body and increases the level of phosphate [30].

In addition, it is claimed that CEE increases the synthesis of muscle protein without increasing protein degradation, resulting in a positive balance in protein storage, causing maximum recovery, hypertrophy and increased strength [15]. Also, CEE may alter the metabolic and hormone responses after resistance exercises by weakening the cortisol response and enhancing insulin and GH responses. However, recent evidence suggested that systemic hormone concentrations cannot progress in the highly desirable intramuscular anabolic environment [15]. The molecular relationship between m-TORC1 and stimulants such as RT, creatine and hormone signals form a complex signaling network that controls cell growth [15].

Nutrition during RT may affect body composition, muscle strength and hormonal secretion. However, the individual effects of CEE have not been well understood by adaptation to RT. Also, most research on creatine has reviewed creatine monohydrate and CEE has been introduced as a novel food by the FDA and few studies have investigated its effects on hormonal changes, body composition, strength, and muscle mass. In addition, the study did not investigate this type of supplement for underweight non-athlete men, and the changes that this supplement could cause in body composition, muscle strength and hormones are not well known; for this reason researchers have considered this study to be necessary.

\section{Materials and methods}

\section{Participants}

This study used a randomized, double-blind, placebo controlled design. Subjects were individuals who had come to the gym to start an RT program for weight gain and muscle mass. Subjects were chosen from among volunteers whose BMI was less than 18.5 (as a slimming scale) and their age range was narrow (young age range). A total of 16 underweight men aged between 17 and 26 years participated in this study.

Subjects were healthy and not resistance trained for at least years. Exclusion criteria included smoking during the last year, use of nutritional supplements or supplemental 
androgens within the last 6 months, current use of statins, recent history of cancer (within 2 years), any metabolic disorder including known electrolyte abnormalities; heart disease, arrhythmias, diabetes, thyroid disease, or hypogonadism and any absolute contraindications to exercise according to American College of Sports Medicine (ACSM) guidelines [18]. Following the informational session, participants completed a medical history questionnaire and signed a written consent form. Participants were instructed to refrain from exercise for $48 \mathrm{~h}$ prior to testing.

Subjects were then randomly assigned to one of two groups: RT with placebo (RT $+\mathrm{PL}, \mathrm{n}=8$, mean age of $20.37 \pm 3.06$ years, mean height of $174.38 \pm 6.71 \mathrm{~cm}$, mean weight of $52.62 \pm 4.89 \mathrm{~kg}$ ); RT with CEE supplementation (RT $+\mathrm{CEE}, \mathrm{n}=8$, mean age of $20.87 \pm 2.16$ years, mean height of $173.0 \pm 4.89 \mathrm{~cm}$, mean weight of $54.12 \pm 3.68 \mathrm{~kg}$ ). 48 hours before and after the training period, blood samples were taken from the subjects; also, the body composition and muscle strength of the subjects were evaluated (Fig. 1). The study was approved by the University Ethics Committee, and conducted according to the Declaration of Helsinki.

\section{Strength assessment}

The leg press and bench press maximal strength tests were performed by the participants to measure any changes in muscular strength during the course of the study. One repetition maximum (1RM) strength tests were performed 48 hours before and after the training period. In the actual measurements, the subjects were carefully familiarized with the test procedures and had several warm-up contractions on all devices. By using multiple repetitions and the following formula, the maximal leg press and bench press were calculated [9]:

$$
\begin{gathered}
1 \mathrm{RM}=(\operatorname{load}(\mathrm{kg})) / \\
(1.0278-[0.0278 \times \text { maximum number of repetitions }]) .
\end{gathered}
$$

\section{Body composition assessment}

Height was measured using standard anthropometry and total body weight was measured using a calibrated scale. BMI was calculated using the following equation: body weight $(\mathrm{kg}) /$ height $^{2}\left(\mathrm{~m}^{2}\right)$. The percentage of body fat was measured using a skinfold caliper (Lafayette, USA) and based on the three point-method on the right side of the body including the chest, abdomen and thigh areas in the three attempts, and was finally determined using the Jackson-Pollack equation [19]. Circumference measurements of the arm and thigh were taken using a measuring tape with the participant wearing only exercise shorts. Arm circumference was measured at the thickest part of the arm on the dominant side. Thigh circumference was measured at the thickest part of the right thigh. The mean

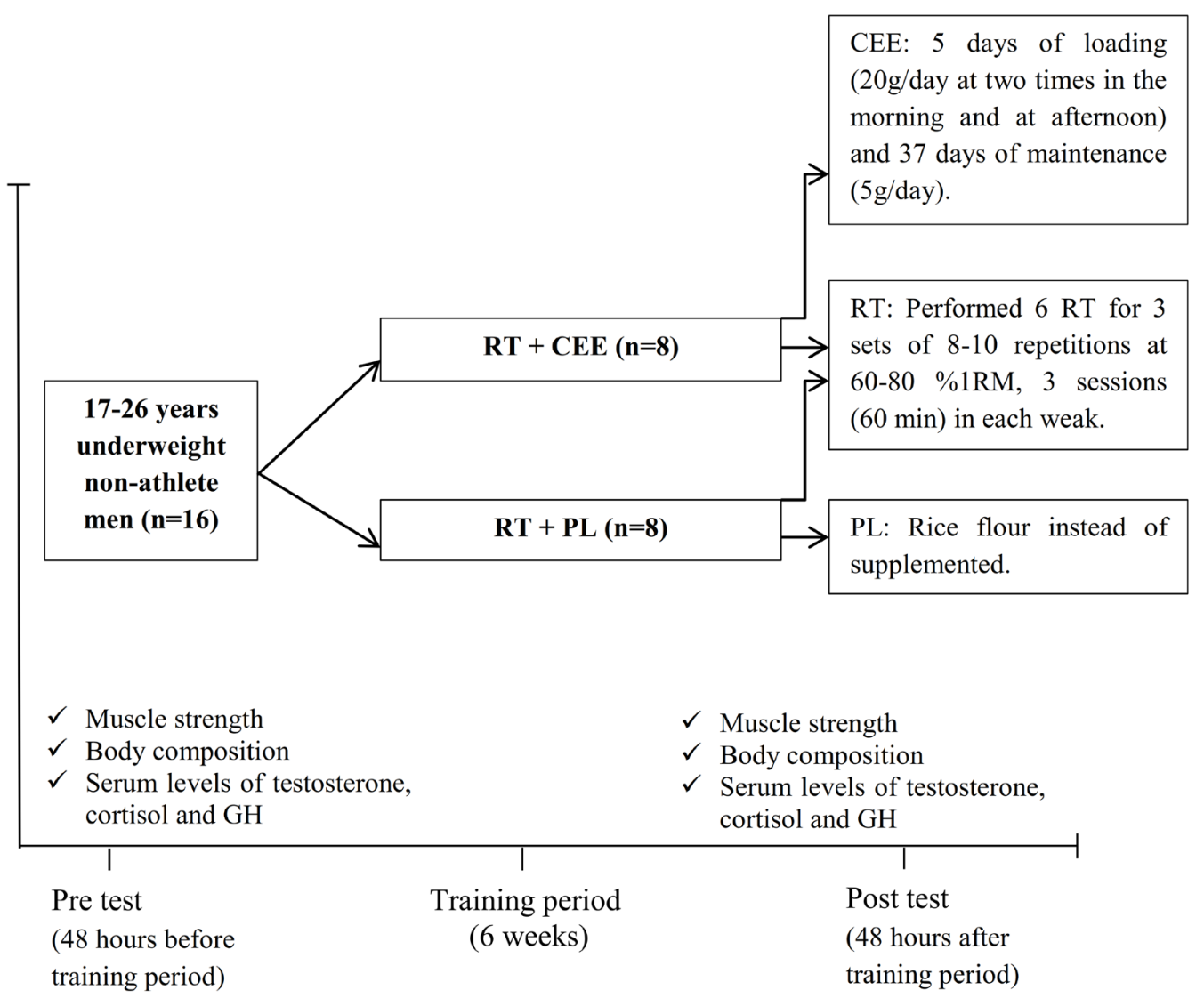

Fig. 1. Study design. Creatine ethyl ester (CEE), placebo (PL), resistance training (RT), growth hormone (GH) 
value of 2 measurements was used in the analyses. All measurements were taken by the same researcher at pre and post-testing laboratory visits [29].

\section{Supplementation protocol}

Subjects of the supplement group received CEE (Labrada Nutritional, USA) for a period of six weeks (42 days), including 5 days of loading (20 grams of CEE per day at two times in the morning and the afternoon) and 37 days of maintenance (each day about 5 grams of CEE). Doses were given in capsule form (each capsule containing 0.5 grams) to be taken at the appointed hours plus $150 \mathrm{cc}$ of water [32] (Fig. 1).

The PL group used rice flour instead of supplementation with capsules, which was not detectable in terms of taste, color or odor from other supplementation. The use of the PL group was similar to that of the CEE group. After the initial baseline assessment of body composition at 48 hours before the training period, supplement dosages were subsequently adjusted based on body composition assessments performed at 48 hours before and after the training period [35].

\section{Resistance training protocol}

Training sessions were supervised and lasted for 6 weeks. Each group met three times per week and participants performed 6 RT for 3 sets of $8-10$ repetitions at $60-80 \% 1 \mathrm{RM}$. The exercises included leg extension, leg flexion, bench press, leg press, lateral pull down, and biceps curl. Rest periods between exercises lasted no longer than three minutes and rest between sets lasted no longer than two minutes. For each two weeks, the first, second and third, 60, 70 and $80 \%$ $1 \mathrm{RM}$ were considered, respectively. The duration of each training session lasted 60 minutes. The training techniques were carefully supervised and the training was controlled throughout the whole RT period.

\section{Blood sampling}

Participants were instructed to refrain from fast for $10 \mathrm{~h}$ prior to blood testing (10 $\mathrm{ml}$ blood sampling). Serum levels of $\mathrm{GH}$, testosterone and cortisol concentrations were determined using commercially available radioimmunoassay (RIA) (Gamma Counter, LKB, Finland) and an Immunotech kit (Czech Republic). The intra- and interassay coefficients of variation (CV) were 3.1, and 8.0\%, respectively, for $\mathrm{GH}$. The intra- and inter-assay $\mathrm{CV}$ were 5.0, and $9.0 \%$, respectively, for testosterone. The intraand inter-assay CV were 4.0 and $8.0 \%$, respectively, for cortisol.

\section{Statistical analysis}

By using the data related to the variables, the mean and standard deviation of scores of participants were calculated by descriptive statistics. The data were found normal by Shapiro-Wilk test. The results are presented as the mean \pm standard deviation. Two-way analysis of variance for repeated measures was performed for all comparisons. Dependent t-tests were performed to determine if baseline values were significantly different between pre - and posttesting. The effect size (ES) was calculated as the posttesting mean minus the pre-testing mean divided by the pooled pre-testing standard deviation. An ES of 0.20-0.49 was considered as small, $0.50-0.79$ as moderate and $\geq 0.80$ as large [12]. Pearson's product-moment correlations coefficient was used to determine relationships between performance variables and hormonal changes. For each variable, a percent change score was calculated ((post-pre)/ pre $\times 100)$. A predetermined $\leq 0.05$ significance level was used for all the analyses.

\section{Results}

\section{Body composition}

A significant difference over the course of the training sessions was observed, demonstrating that weight significantly increased at pre-test and post-tests (RT + CEE: $\mathrm{p}=0.002 ; \mathrm{RT}+\mathrm{PL}: \mathrm{p}=0.01)$. Fat percentage decreased in the RT + CEE and RT + PL groups after the training period, but the observed changes were not significant in the RT + CEE group $(p=0.74)$. To the contrary, there were significant difference between RT + CEE groups with $\mathrm{RT}+\mathrm{PL}$ for weight and fat percent $(\mathrm{p}<0.001, \mathrm{p}=0.05$; respectively). The decrease in fat percentage was greater in the RT + PL group than in the RT + CEE group $(\%$ change $=-6.78$ vs. -0.76 , respectively) (Table 1$)$.

\section{Circumferences}

Circumferences of the arm and thigh were measured pre - and post-testing. For circumferences of the arm and thigh significant increases were observed between pre-test and post-test in the RT + CEE group $(p=0.01, p=0.007$; respectively). However, there were no significant differences between groups ( $\mathrm{p}=0.51, \mathrm{p}=0.25$; respectively) (Table 1).

\section{Muscle strength}

For bench press and leg press strength, significant increases were observed between pre - and post-testing in the two groups $(\mathrm{p}<0.001)$. By contrast, there was no significant difference for bench press between groups $(\mathrm{p}=0.07)$, but leg press strength was significantly higher in the RT + CEE group compared to the RT + PL group $(\mathrm{p}=0.001)($ Table 1$)$.

\section{Hormones}

Data for serum GH, testosterone and cortisol concentrations are presented in Table 1. Significant increase were 
Table 1. Changes in body composition, muscle strength and hormonal responses to 6-week training intervention (mean \pm SD)

\begin{tabular}{|c|c|c|c|c|c|c|c|c|}
\hline & \multicolumn{4}{|c|}{$\mathrm{RT}+\mathrm{PL}(\mathrm{n}=8)$} & \multicolumn{4}{|c|}{$\mathrm{RT}+\mathrm{CEE}(\mathrm{n}=8)$} \\
\hline Variable & Pre-test & Post-test & $\%$ Change & Effect size & Pre-test & Post-test & $\%$ Change & Effect size \\
\hline Weight [kg] & $52.62 \pm 4.89$ & $53.43 \pm 5.00 *$ & 1.54 & 0.16 & $54.12 \pm 3.68$ & $58.81 \pm 3.97 *$ *\# & 8.66 & 1.22 \\
\hline Fat $[\%]$ & $12.52 \pm 2.78$ & $11.67 \pm 2.30 *$ & -6.78 & -0.33 & $11.80 \pm 2.33$ & $11.71 \pm 1.72$ & -0.76 & -0.04 \\
\hline $\begin{array}{l}\text { Circumference } \\
\text { thigh }[\mathrm{cm}]\end{array}$ & $44.50 \pm 5.26$ & $45.00 \pm 5.58$ & 1.13 & 0.09 & $43.50 \pm 3.89$ & $44.50 \pm 3.50 *$ & 2.29 & 0.27 \\
\hline $\begin{array}{l}\text { Circumference } \\
\operatorname{arm}[\mathrm{cm}]\end{array}$ & $22.62 \pm 2.97$ & $23.00 \pm 2.82$ & 1.67 & 0.13 & $21.62 \pm 2.66$ & $22.25 \pm 2.37 *$ & 2.91 & 0.25 \\
\hline Bench press $[\mathrm{kg}]$ & $31.25 \pm 6.40$ & $36.25 \pm 6.40 *$ & 16 & 0.78 & $28.75 \pm 5.17$ & $36.87 \pm 3.72 *$ & 28.24 & 1.80 \\
\hline Leg press $[\mathrm{kg}]$ & $102.50 \pm 14.88$ & $106.75 \pm 13.06 *$ & 4.14 & 0.30 & $106.25 \pm 16.85$ & $123.12 \pm 14.37 *$ & 15.87 & 1.07 \\
\hline $\begin{array}{l}\text { Testosterone } \\
{[\mathrm{nmol} / 1]}\end{array}$ & $11.35 \pm 2.25$ & $11.99 \pm 2.24 *$ & 5.63 & 0.28 & $11.78 \pm 1.58$ & $12.93 \pm 1.41 *$ & 9.76 & 0.76 \\
\hline $\mathrm{GH}[\mu \mathrm{g} / 1]$ & $0.85 \pm 0.37$ & $1.00 \pm 0.37 *$ & 17.64 & 0.40 & $0.77 \pm 0.37$ & $1.03 \pm 0.37 *$ & 33.76 & 0.70 \\
\hline Cortisol [nmol/1] & $330.12 \pm 36.21$ & $324.88 \pm 38.15 *$ & -1.58 & -0.14 & $315.12 \pm 50.87$ & $306.5 \pm 46.85 *$ & -2.73 & -0.17 \\
\hline
\end{tabular}

* - denotes significant differences between baseline and post-testing values $(\mathrm{p} \leq 0.05)$; $\#-$ denotes significant differences between the RT $+\mathrm{CEE}$ and RT + PL groups at post-testing $(\mathrm{p} \leq 0.05)$. Resistance training $(\mathrm{RT})$, Creatine ethyl ester (CEE), placebo (PL), growth hormone (GH).

Table 2. Relationships between hormonal measures with muscle strength and muscle mass in the post-testing intervention $(\mathrm{n}=16)$

\begin{tabular}{lcccc}
\hline & Circumference thigh [cm] & Circumference arm [cm] & Bench press [kg] & Leg press [kg] \\
\hline \multirow{2}{*}{ Testosterone [nmol/1] } & $\mathrm{r}=-0.15$ & $\mathrm{r}=-0.01$ & $\mathrm{r}=0.13$ & $\mathrm{r}=-0.02$ \\
& $\mathrm{p}=0.57$ & $\mathrm{p}=0.95$ & $\mathrm{p}=0.62$ & $\mathrm{p}=0.93$ \\
$\mathrm{GH}[\mu \mathrm{g} / \mathrm{l}]$ & $\mathrm{r}=-0.13$ & $\mathrm{r}=-0.23$ & $\mathrm{r}=0.03$ & $\mathrm{r}=-0.10$ \\
& $\mathrm{p}=0.60$ & $\mathrm{p}=0.38$ & $\mathrm{p}=0.89$ & $\mathrm{p}=0.70$ \\
Cortisol [nmol/1] & $\mathrm{r}=0.04$ & $\mathrm{r}=-0.38$ & $\mathrm{r}=-0.18$ & $\mathrm{r}=-0.17$ \\
& $\mathrm{p}=0.86$ & $\mathrm{p}=0.14$ & $\mathrm{p}=0.49$ & $\mathrm{p}=0.51$ \\
\hline
\end{tabular}

GH - Growth hormone.

observed for concentrations of $\mathrm{GH}$ and testosterone between pre- and post-test in the RT + CEE and RT + PL groups $(\mathrm{GH}$; RT $+\mathrm{CEE}: \mathrm{p}<0.001, \mathrm{RT}+\mathrm{PL}: \mathrm{p}=0.01$, testosterone; RT + CEE: $p=0.007, \mathrm{RT}+\mathrm{PL}: \mathrm{p}=0.01)$. Also, cortisol level was significantly decreased in the post-test in the RT + CEE and RT + PL groups (cortisol; RT + CEE: $\mathrm{p}=0.005, \mathrm{RT}+\mathrm{PL}: \mathrm{p}=0.03)$. The analysis indicated that $\mathrm{GH}$ was greater in the RT $+\mathrm{CEE}$ group compared to the RT + PL group. However, there were no significant differences between groups with regards to $\mathrm{GH}$, cortisol and testosterone $(\mathrm{p}=0.06, \mathrm{p}=0.26, \mathrm{p}=0.17$, respectively) (Table 1).

As shown in Table 2, there were no significant correlations of hormonal measures with muscle strength and circumferences of the arm and thigh in the post-testing intervention $(p>0.05)$.

\section{Discussion}

The purpose of this study was to investigate the effect of CEE supplementation during an RT course on hormonal changes, body composition, and muscle strength of underweight non-athlete men. The results showed that the pre - and post-test variations were significant in most variables; in addition, weight and leg strength changes in the RT + CEE group were significant compared to the RT + PL group. However, in other variables, despite the increase in the RT + CEE group, no significant changes were observed between the two groups.

Studies conducted over the past decades have shown that creatine supplementation has different effects on the physiology and metabolism of skeletal muscle, including 
increased muscle mass (hypertrophy). A review study by Farshidfar et al. [15] showed that creatine supplementation stimulates anabolic pathways for protein synthesis. The results of this study indicated that hormonal changes after the training period were significant in both groups; however, despite the further increases of GH and testosterone levels and lower levels of cortisol in the RT + CEE group compared to the RT + PL group, the differences between the two groups were not significant. There is not much research on the effect of CEE supplementation on hormonal levels, and most studies have been conducted on creatine monohydrate supplementation. In this regard, the results of Arazi et al. [2] showed that creatine supplementation consumption more than 5 days a week combined with RT is sufficient to increase the concentration of testosterone levels and reduce the concentration of cortisol. Also, the results of Deldicque et al. [14] showed that creatine supplementation does not increase protein synthesis more than exercise alone. They reported that creatine supplements increase the expression of IGF-1, but did not show any increase after the exercise, and any increase in muscle growth is probably due to an increase in the anabolic state of the cell and IGF. In addition, the results of Cooke et al. [13] showed that consuming creatine monohydrate and carbohydrates does not significantly change IGF-1 and testosterone levels in older men. In contrast, the results of Volek et al. [39] did not show any significant changes in the status of endocrine hormones after taking creatine supplement with RT. The reason for these differences may be different blood sampling methods, as well as the training status of the subjects, which slows down the rate of changes in the anabolic hormones.

Testosterone is a hormone that plays a key role in the metabolism of carbohydrates, lipids and proteins. It has been shown that sometimes testosterone has a lot of effects on the composition of body fat and muscle mass in men [22]. Testosterone deficiency is associated with increased body fat (especially central fat), reduced insulin sensitivity, decreased glucose tolerance, increased cholesterol and triglycerides and reduced HDL cholesterol. The effects of testosterone are different among most tissues (muscles, fat and liver) that play a role in insulin activity and it seems that there are complex regulatory effects on the metabolism [22]. It is a hormone produced by cholesterol, which has significant anabolic effects in muscle tissue. The promotion of anabolism occurs by increasing protein synthesis and inhibiting protein degradation [31]. Testosterone may also help increasing protein indirectly by stimulating the release of other anabolic hormones such as GH. In addition, it has been shown that it increases the transcription and activation of the satellite cells, thereby increasing the number of myogenically committed satellite cells [31]. GH has various metabolic effects, including increased protein synthesis, lipolysis, and glucose uptake, and regulates protein anabolism through the mechanisms of IGF-1 dependent on the endocrine and paracrine mechanism as the independent pathway to IGF-1 [8]. Contrary to these two hormones, cortisol is a catabolic hormone and is associated with an increase in the amount of protein catabolism, which can have an effect on the prevention of skeletal muscle hypertrophy [8]. Serum cortisol levels are affected by various factors such as intensity, duration, exercise time, type of exercise, age, height, ambient temperature and psychological state [5].

Our results on muscle strength indicated that strength increased due to consumption of CEE combined with RT. Compared to the two groups, only the strength of leg muscles showed significant changes. Also, in the case of muscle mass, the results showed that leg and arm muscle masses were significantly increased in the RT + CEE group, but no significant changes were observed in the RT + PL group. In similar studies, Jose [21] showed that after four weeks of RT, when creatine supplementation was consumed immediately after exercise, it increased their strength. Gualano et al. [16], studying the effect of creatine supplementation and RT, concluded that creatine monohydrate consumption and RT for 24 weeks improved muscle mass and muscle function. Also, Lanhers et al. [25] in their review study concluded that creatine supplementation would increase strength of the upper body (bench press) in activities lasting less than 3 minutes. Study Nunes et al. [28] suggested an increase in muscle hypertrophy, especially in the upper body, due to the use of creatine supplementation in young men practicing RT.

Contrary to these results, Young [41] suggested that creatine supplementation has no effect on muscle mass, function or muscle hypertrophy. In this study, creatine monohydrate supplementation was used for 5 weeks. Also, the results of Spillane et al. [35] showed that CEE supplementation in non-RT males did not show more effects on muscle strength or functioning, fat mass and thigh mass muscle compared to creatine monohydrate or the maltodextrin placebo. Bemben et al. [4] stated that RT in middle-aged and elderly men increased muscle strength and muscle mass; furthermore, consumption of creatine and protein had no additional effects.

Muscle mass is one of the main determinants of strength and power [29]. Any increase in strength may have been entirely for physiological reasons and changes in hypertrophy in exercised muscles, and is not related to improving muscle neuromuscular coordination. Shelmadine et al. [33] observed significant increases in markers of satellite cell activation and hypertrophy and a modest increase in fat free mass in the group which used supplementation after only 4 weeks in untrained men. Furthermore, Snow et al. [34] examined the effect of creatine supplementation $(0.8 \mathrm{~g} / \mathrm{kg}$ body weight $)$ and moderate intensity RT on the phosphorylation status of some proteins 
involved in the AKT/PKB pathway. Their results indicated that the state of phosphorylation of AKT/PKB and GSK3 $\beta$ increased significantly in the supplement group in 1 to 5 days. The study of Bonilla [6] showed that the ergogenic effect of creatine supplementation is absolutely dependent on the storage of creatine in myocytes and the secondary optimization of the $\mathrm{Cr} / \mathrm{PCr} / \mathrm{CK}$ system, which acts as a spatial/temporal buffer for ATP regeneration near myocellular ATPases. In addition, this improvement in energy homeostasis induces positive regulation of anabolic centers (such as IGF-1 and MAPK), which trigger muscle growth and increase strength [6]. Creatine increases the in vitro biosynthesis of muscle myosin, up-regulates satellite cell activity, and increases transcription of factors involved in muscle hypertrophy [6]. Creatine increases muscle fibers and reduces the protein breakdown of the entire body. In addition, studies have shown that creatine supplementation can regulate transcription of myogenic regulators (such as IGF-1, myogenin, MRF-4, MYF-5), and increase the efficacy of protein transfer and activation, as well as proliferation and differentiation of satellite cells; this ultimately results in a positive balance in protein synthesis [6]. In contrast, it has been shown that short-term creatine supplementation with RT does not affect the protein balance of young people [14]. The findings of these studies are controversial and may be influenced by various techniques used to measure the association between the acute hormonal response and subsequent muscular hypertrophy [26].

Furthermore, we observed weight gain in both groups, and significant changes were observed between the two groups. In contrast, there was a decrease in fat percentage in the RT + CEE group after the training period, but the observed change was not significant. In addition, fat percent differences between the two groups were significant. In this regard, the results of Cooke et al. [13] showed that consumption of creatine monohydrate and carbohydrate significantly increased body weight after 12 weeks of RT. In addition, fat percentage was significantly higher in the carbohydrate group than in the creatine monohydrate group and carbohydrate group. Also, the results of Spillane et al. [35] showed significant changes in body composition (body weight, fat mass, fat free mass) in the creatine monohydrate group and CEE, but no significant differences were observed between the groups. They stated that CEE was not effective in improving body composition compared to creatine monohydrate, and improvement of these variables might be due to the protocol used [35]. The results of Candow et al. [11] showed that subjects consuming creatine supplement experienced weight gain. One of the ergogenic effects of creatine supplementation is increased body mass. A meta-analysis study showed that approximately $64 \%$ of studies that measured body mass reported significant changes due to creatine supplementation. The increase in body mass appears to be due to the increase of intracellular water associated with fluid shifts due to the osmotic properties of creatine [7].

Contrary to the results of the present study regarding weight gain in the RT + CEE group, Jose [21] concluded that total creatine supplementation with RT did not cause significant changes in body weight and fat free mass after four weeks of RT and creatine consumption. Similarly, Jagim et al. [20] found that creatine monohydrate consumption did not significantly reduce body fat percentage in subjects, and despite the increase in weight, the observed changes were not significant.

CEE seems to increase the bioavailability of creatine and muscle creatine levels. Studies showed that CEE is a substrate for creatine kinase. However, recent studies showed that CEE is converted to creatinine, not creatine [17]. Muscle glycogen levels may also be affected by creatine supplementation, which is probably due to increased volume of cellular water. It has been reported that increased body mass due to creatine supplementation is due to decreased urine output and water retention during the early stages of creatine loading [17].

One limitation of the current study was the lack of evaluation of dietary intake and accurate evaluation of muscle volume. Another limitation of the present study was the small sample size. Future studies are required to examine in detail the daily diet and use a larger sample size. Also, using accurate evaluation of muscle volume with new methods may be helpful.

\section{Conclusions}

Based on the results, it seems that consumption of CEE combined with RT can have positive effects on body weight and leg strength in underweight non-athlete men and does not affect hormonal levels and other variables. More research is needed to make more detailed comments on this subject.

\section{Conflict of interest: Authors state no conflict of interest.}

\section{References}

1. Andres S., Ziegenhagen R., Trefflich I., Pevny S., Schultrich K., Braun H., Lampen A. (2017) Creatine and creatine forms intended for sports nutrition. Mol. Nutr. Food. Res., 61(6). DOI: 10.1002/mnfr.201600772.

2. Arazi H., Rahmaninia F., Hosseini K., Asadi A. (2015) Effects of short term creatine supplementation and resistance exercises on resting hormonal and cardiovascular responses. Sci. Sport, 30(2): 105-109. DOI: 10.1016/j. scispo.2014.03.006. 
3. Bemben M., Lamont H. (2005) Creatine supplementation and exercise performance. Recent findings. Sports Med., 35(2): 107-125. DOI: 10.2165/00007256-20053502000002.

4. Bemben M.G., Witten M.S., Carter J.M., Eliot K.A., Knehans A.W., Bemben D.A. (2010) The effects of supplementation with creatine and protein on muscle strength following a traditional resistance training program in middle-aged and older men. J. Nutr. Health. Aging, 14(2): 155-159. DOI: 10.1007/s12603-009-0124-8.

5. Beyleroglu M. (2011) The effects of maximal aerobic exercise on cortisol and thyroid hormones in male field hockey players. Afr. J. Pharm. Pharmacol., 5(17): 2002-2006. DOI: 10.5897/AJPP11.229.

6. Bonilla D.A., Moreno Y. (2015) Molecular and metabolic insights of creatine supplementation on resistance training. Rev. Colomb. Quim., 44(1): 11-18. DOI: 10.15446/ rev.colomb.quim.v44n1.53978.

7. Branch J.D. (2003) Effect of creatine supplementation on body composition and performance: a meta-analysis. Int. J. Sport. Nutr. Exerc. Metab., 13(2): 198-226. DOI: 10.1123/ijsnem.13.2.198.

8. Brown L.E. (2017) Strength training, National Strength and Conditioning Association. Human Kinetics.

9. Brzycki M. (1993) Strength testing-Predicting a one-rep max from a reps-to-fatigue. J. Phys. Health. Edu. Recreat., 64(1): 88-90. DOI: 10.1080/07303084.1993.10606 684.

10. Buford T.W., Kreider R.B., Stout J.R., Greenwood M., Campbell B., Spano M., Antonio J. (2007) International Society of Sports Nutrition position stand: creatine supplementation and exercise. J. Int. Soc. Sports Nutr., 4(1): 6. DOI: 10.1186/1550-2783-4-6.

11. Candow D.G., Little J.P., Chilibeck P.D., Abeysekara S., Zello G.A., Kazachkov M., Yu P.H. (2008) Low-dose creatine combined with protein during resistance training in older men. Med. Sci. Sports Exerc., 40(9): 1645-1652. DOI: 10.1249/MSS.0b013e318176b310.

12. Cohen J. (1988) Statistical Power Analysis for the Behavioral Sciences. 2nd ed. Hillsdale: Routledge.

13. Cooke M.B., Brabham B., Buford T.W., Shelmadine B.D., McPheeters M., Hudson G.M., Willoughby D.S. (2014) Creatine supplementation post-exercise does not enhance training-induced adaptations in middle to older aged males. Eur. J. Appl. Physiol., 114(6): 1321-1332. DOI: 10.1007/s00421-014-2866-1.

14. Deldicque L., Louis M., Theisen D., Nielens H., Dehoux M., Thissen J.P., Francaux M. (2005) Increased IGF mRNA in human skeletal muscle after creatine supplementation. Med. Sci. Sports Exerc., 37(5): 731-736. DOI: 10.1249/01.MSS.0000162690.39830.27.

15. Farshidfar F., Pinder M.A., Myrie S.B. (2017) Creatine supplementation and skeletal muscle metabolism for building muscle mass-review of the potential mechanisms of action. Curr. Protein. Pept. Sci., 18(12): 1273-1287. DOI: $10.2174 / 1389203718666170606105108$.

16. Gualano B., Macedo A.R., Alves C.R.R., Roschel H., Benatti F.B., Takayama L., Pereira R.M.R. (2014) Creatine supplementation and resistance training in vulnerable older women: a randomized double-blind placebocontrolled clinical trial. Exp. Gerontol., 53: 7-15). DOI: 10.1016/j.exger.2014.02.003.

17. Hall M., Trojian T.H. (2013) Creatine supplementation. Curr. Sports. Med. Rep., 12(4): 240-244. DOI: 10.1249/ JSR.0b013e31829cdff2.

18. Ives S.J., Norton C., Miller V., Minicucci O., Robinson J., O’Brien G., Rose K. (2017) Multi-modal exercise training and protein-pacing enhances physical performance adaptations independent of growth hormone and BDNF but may be dependent on IGF-1 in exercise-trained men. Growth. Horm. IGF. Res., 32: 60-70. DOI: 10.1016/j. ghir.2016.10.002.

19. Jackson A.S., Pollock M.L. (1978) Generalized equations for predicting body density of men. Br. J. Nutr., 40(3): 497-50. DOI: 10.1079/BJN19780152.

20. Jagim A.R., Oliver J.M., Sanchez A., Galvan E., Fluckey J., Riechman S., Kreider R.B. (2012) A buffered form of creatine does not promote greater changes in muscle creatine content, body composition, or training adaptations than creatine monohydrate. J. Int. Soc. Sports Nutr., 9(1): 43. DOI: 10.1186/1550-2783-9-43.

21. Jose A. (2013) The effects of preversus post workout supplementation of creatine monohydrate on body composition and strength. J. Int. Soc. Sports Nutr., 10(1): 36. DOI: $10.5897 / A J P P 11.229$.

22. Kelly D.M., Jones T.H. (2013) Testosterone: a metabolic hormone in health and disease. J. Endocrinol., 217(3): R25-R45. DOI: 10.1530/JOE-12-0455.

23. Kraemer W.J., Beeler M.K., Post E.M., Luk H.Y., Lombard J.R., Dunn-Lewis C., Volek J.S. (2019) Physiological Basis for Creatine Supplementation in Skeletal Muscle and the Central Nervous System. In Nutrition and Enhanced Sports Performance. Academic. Press, 581-594. DOI: 10.1016/B978-0-12-813922-6.00049-7.

24. Kraemer W.J., Ratamess N.A. (2005) Hormonal responses and adaptations to resistance exercise and training. Sports Med., 35(4): 339-361. DOI: 10.2165/00007256200535040-00004.

25. Lanhers C., Pereira B., Naughton G., Trousselard M., Lesage F.X., Dutheil F. (2017) Creatine Supplementation and Upper Limb Strength Performance: A Systematic Review and Meta-Analysis. Sports Med., 47(1): 163-173. DOI: 10.1007/s40279-016-0571-4.

26. Mangine G.T., Hoffman J.R., Gonzalez A.M., Townsend J.R., Wells A.J., Jajtner A.R., LaMonica M.B. (2017) Exercise-Induced Hormone Elevations Are Related to Muscle Growth. J. Strength. Cond. Res., 31(1): 45-53. DOI: 10.1519/JSC.0000000000001491. 
27. Negro M., Avanzato I., D’Antona G. (2019) Creatine in Skeletal Muscle Physiology. In Nonvitamin and Nonmineral Nutritional Supplements. Academic Press, 59-68. DOI: 10.1016/B978-0-12-812491-8.00008-4.

28. Nunes J.P., Ribeiro A.S., Schoenfeld B.J., Tomeleri C.M., Avelar A., Trindade M.C., Carvalho F.O. (2017) Creatine supplementation elicits greater muscle hypertrophy in upper than lower limbs and trunk in resistance-trained men. Nutr. Health, 23(4): 223-229. DOI: 10.1177/0260106017737013.

29. Ormsbee M.J., Mandler W.K., Thomas D.D., Ward E.G., Kinsey A.W., Simonavice E., Kim J.S. (2012) The effects of six weeks of supplementation with multi-ingredient performance supplements and resistance training on anabolic hormones, body composition, strength, and power in resistance-trained men. J. Int. Soc. Sport Nutr., 9(1): 49. DOI: 10.1186/1550-2783-9-49.

30. Ravera S., Adriano E., Balestrino M., Panfoli I. (2012) Creatine ethyl ester: a new substrate for creatine kinase. Mol. Biol., 46(1): 149-152. DOI: 10.1134/ S0026893312010190.

31. Schoenfeld B.J. (2010) The mechanisms of muscle hypertrophy and their application to resistance training. $J$. Strength. Cond. Res., 24(10): 2857-2872. DOI: 10.1519/ JSC.0b013e3181e840f3.

32. Shao A., Hathcock J.N. (2006) Risk assessment for creatine monohydrate. Regul. Toxicol. Pharm., 45(3): 242-251. DOI: 10.1016/j.yrtph.2006.05.005.

33. Shelmadine B., Cooke M., Buford T., Hudson G., Redd L., Leutholtz B., Willoughby D.S. (2009) Effects of 28 days of resistance exercise and consuming a commercially available pre-workout supplement, NO-Shotgun (R), on body composition, muscle strength and mass, markers of satellite cell activation, and clinical safety markers in males. J. Int. Soc. Sport Nutr., 6(1): 13. DOI: 10.1186/1550-2783-6-16.

34. Snow R., Wright C., Quick M., Garnham A., Watt K., Russell A. (2004) The effects of acute exercise and creatine supplementation on akt signalling in human skeletal muscle. Mol. Cell., 14: 395-403.

35. Spillane M., Schoch R., Cooke M., Harvey T., Greenwood M., Kreider R., Willoughby D.S. (2009) The effects of creatine ethyl ester supplementation combined with heavy resistance training on body composition, muscle performance, and serum and muscle creatine levels. J. Int. Soc. Sport Nutr., 6(1): 6. DOI: 10.1186/1550-2783-6-6.

36. Stefani G.P., Nunes R.B., Dornelles A.Z., Alves J.P., Piva M.O., Di Domenico M., Dal Lago P. (2014) Effects of creatine supplementation associated with resistance training on oxidative stress in different tissues of rats. J. Int. Soc. Sport Nutr., 11(1): 11. DOI: 10.1186/1550-2783-11-11.

37. Tyka A.K., Chwastowski M., Cison T., Palka T., Tyka A., Szygula Z., Cepero M. (2015) Effect of creatine malate supplementation on physical performance, body composition and selected hormone levels in spinters and longdistance runners. Acta. Physiol. Hung., 102(1): 114-122. DOI: 10.1556/APhysiol.102.2015.1.12.

38. Valenzuela P.L., Morales J.S., Emanuele E., ParejaGaleano H., Lucia A. (2019) Supplements with purported effects on muscle mass and strength. Eur. J. Nutr., 1-26. DOI: 10.1007/s00394-018-1882-z.

39. Volek J.S., Boetes M., Bush J.A., Putukian M., Sebastianelli W.J., Kraemer W.J. (1997) Response of testosterone and cortisol concentrations to high-intensity resistance exercise following creatine supplementation. J. Strength. Cond. Res., 11(3): 182-7. DOI: 10.1519/00124278199708000-00009.

40. Westcott W.L. (2012) Resistance training is medicine: effects of strength training on health. Curr. Sports. Med.Rep., 11(4): 209-216. DOI: 10.1249/JSR.0b013e31825dabb8.

41. Young R.E., Young J.C. (2007) The effect of creatine supplementation on mass and performance of rat skeletal muscle. Life Sci., 81(9): 710-716. DOI: 10.1016/j. lfs.2007.06.029.

\section{Received13.09.2019 \\ Accepted 05.11.2019}

(C) University of Physical Education, Warsaw, Poland

\section{Acknowledgments}

The authors hereby declare their gratitude to all those who participated as subjects in this study. 